\title{
“THIS IS MY RESPONSIBILITY”: PARENTAL EXPERIENCE OF FORMER SOVIET UNION IMMIGRANT PARENTS IN ISRAEL
}

\author{
Liat Yakhnich
}

\begin{abstract}
This qualitative study focuses on the parenting experience of immigrant parents from the former Soviet Union (FSU) in Israel. Seventeen in-depth open interviews with FSU immigrant parents were conducted. All participants had been living in Israel between one-and-a-half and five years and had adolescent children aged 11 to 17 . The central theme that emerges from the interviews is the participants' sense of parental responsibility, which is based on four central components: control, involvement, discipline, and parental guidance. Immigration challenges the participants' abilities to fulfil their responsibilities as parents by exposing them and their children to cultural differences in child-rearing practices and language difficulties. Pressures of work and learning to live in a new culture may lead to a lack of emotional and physical availability to their children. Participants try to cope with these challenges by maintaining child-rearing practices used in the FSU. Many parents report this means of coping as unsuccessful and feel helpless and uncertain in tackling new parental dilemmas posed by immigration.
\end{abstract}

Keywords: parenting, immigration, parenting styles, parental responsibility

Liat Yakhnich, $\mathrm{PhD}$ is a lecturer in the Youth Development Department, Beit Berl Academic College, Beit Berl 49905, Israel. E-mail: liatyakhnich@yahoo.com 
Since 1989, Israel has absorbed over a million immigrants from the former Soviet Union (FSU), who now constitute approximately 15\% of the Israeli population (Horenczyk \& Ben-Shalom, 2006). In recent years the rate of immigration from the FSU has fallen to about 8,000 immigrants per year; however, this is still the largest immigrant group in Israel. The children of FSU immigrants account for approximately $5 \%$ of all minors in the country (Cosher, Ben-Arie, \& Cohen, 2011). FSU-origin children and adolescents have generated considerable interest among Israeli researchers during the last two decades. Studies of this group reveal a relatively high incidence of distress and adversity, as well as of problematic and even risk-taking behavior (Cosher et al., 2011; Edelstein \& Bar-Hamburger, 2007; Horowitz \& Brosh, 2011; Mirsky, 2012). These phenomena are generally attributed, at least in part, to changing parent-child relationships and the decreasing influence that immigrant parents have on their children (Mann, 2004; Horowitz \& Brosh, 2011; Edelstein \& BarHamburger , 2007; Yakhnich \& Teichman, 2015). As immigrant families’ adaptation involves coping with multiple stressors in various aspects of life, immigrant parents“ psychological wellbeing, functioning, and ability to interact positively with their children may be challenged (Yakhnich, 2008). Some additional factors that potentially affect FSU immigrant families are generally low socio-economic status, increased divorce rates and large number of single-parent households, and loss of the support of grandparents who stayed in the FSU (Kosner, Roer-Strier, \& Kurman, 2014). Given that the majority of studies examining immigrant parent-child relationships are focused on immigrant children's adjustment, it would be of special interest to examine the effects of migration and transition on immigrant parents. Therefore, the aim of this study is to explore FSU immigrants' parenting experience in a period of adaptation and cultural transition.

\section{Parenting}

Parenting is defined as the process of promoting and supporting the physical, emotional, social, and intellectual development of a child from infancy to adulthood (Davies, 2000). The parental role is based on a special interpersonal relationship characterized by practically unlimited commitment, responsibility, and emotional and physical nurturing (Cohen, 2007). Studies on parenting point out its paradoxical characteristics: for many parents it is a source of joy and self-realization accompanied by pleasure and intense emotional experiences; however, parenting is also related to low levels of personal wellbeing and satisfaction, and to high levels of stress and anxiety (Galatzer-Levy, Mazursky, Mancini, \& Bonanno, 2011; Jokela, Kivimaki, Elovainio, \& Keltikangas-Jarvinen, 2009).

One significant aspect of parenting that has received wide attention in the literature is parenting style. Baumrind (1978) first described three parenting styles characterized by various levels of parental acceptance and control: authoritative, authoritarian, and permissive. The authoritative style is based on high levels of parental acceptance and control. Authoritative parents set realistic demands and expectations for their children, while accepting them and meeting their needs. They explain their demands and strive to achieve internalization of behavioral rules and limits. The authoritarian style is also based on a high level of control; however, authoritarian parents prefer discipline over acceptance. Their childrearing practices are punitive and restrictive. The permissive style is based on low control and high acceptance levels, and is characterized by having few behavioral expectations for the child. Later, an additional neglectful parenting style was added to the model. It is based on low levels of both control and acceptance, and is characterized by lack of parental involvement in children's lives (Maccoby \& Martin, 1983). Studies consistently point to the advantages of authoritative parenting as manifested in children's adaptive behavior, academic 
success, psychological maturity (Rinaldi \& Howe, 2012; Steinberg, Elmen \& Mounts, 1989), emotional autonomy and leadership skills (Kudo, Longhofer \& Floersch, 2012). However, the effectiveness of parenting style depends on the cultural context and on how it is perceived by the child. For example, authoritarian parenting is associated with notions of care and love in many cultural groups (Dwairy \& Dor, 2009).

The issue of parenting styles is particularly relevant to the present study, as immigrant parents' adaptation is closely connected to the parenting approaches characteristic of their culture of origin and their congruity with parenting practices existing in the host society (Roer-Strier \& Rosenthal, 2001). Major differences between child-rearing goals and methods accepted in the home culture and those prevalent in the host society may lead to family conflict, deepen the gaps between immigrant parents and their children, and increase parents' sense of disorientation and distress.

A variety of factors influence parental functioning, wellbeing, and satisfaction. One of the main factors known to have a negative influence on parental functioning is stress (Farmer \& Lee, 2011; Waylen \& Stewart-Brown, 2010). When parents are cognitively and emotionally exhausted, their parental functioning is impaired, and they are less able to mobilize effort, attention, and support for their children (Browne, Meunier, O’Connor, \& Jenkins, 2012). A wide range of life events may cause parental stress. Immigration, common in contemporary society, is one of these: it involves coping with multiple stressors, such as employment, language, housing problems (Yakhnich, 2008), and exposes the immigrants to high levels of mental and physical distress (Ritsner, Modai, \& Ponizovsky, 2000).

\section{Parenting Adolescents}

The transition to adolescence confronts parents with new developmental goals and challenges, as their children distance themselves from parental influence and devote an increasing proportion of their time to interactions outside the family (Collins \& Laursen, 2004). Yet, parental involvement is viewed as an important determinant of youth's normal development. As the parent-adolescent relationship undergoes renegotiation and adolescents seek more autonomy, the nature of the involvement may change. Parents are expected to reduce involvement in strategies that may be perceived as intrusive and to increase involvement in strategies that promote youth's independence and decision-making ability (Bhargava \& Witherspoon, 2015).

A central characteristic of adolescence is youth's tendency to challenge parental authority, leading to higher levels of family conflict. Most such conflict revolves around everyday family matters and indicates adolescents' desire for autonomy and independence (Moed et al., 2014). Conflict is seen as evidencing a transformation from unilateral to more mutual relations of young adulthood; in the context of warm, accepting relationships, it is considered to be adaptive for development (Yau \& Smetana, 2003). It should be noted that adolescent-parent conflict may reflect the emphasis placed by Western culture on independence and achievement of personal goals, and that in collectivist cultures it may be comparatively muted (Yau \& Smetana, 2003).

Despite high levels of interpersonal conflict, maintaining high-quality relationships with family has important implications for adolescents' mental and physical health (Ehrlich, Hoyt, Sumner, McDade, \& Adam, 2015; Kahn, Holmes, Farley, \& Kim-Spoon, 2015). Parent-adolescent relationship quality is significantly influenced by such parenting practices as warmth, responsiveness, positive reinforcement, behavioral control, and openness in communication (Kahn, et al., 2015; Kearney \& Bussey, 2014). 


\section{Parenting and parent-child relationships in immigration}

A wide body of literature examines the link between immigration, parent-child relationships, and immigrant children's and adolescents' adaptation. Immigrant parents' psychological distress was found to predict their children's mental health problems (RavensSieberer, Erhart, Gosch, \& Wille, 2008; Sowa, Crijnen, Bengi-Arslan, \& Verhulst, 2000), while their failure to learn the new language is believed to negatively affect their authority and their ability to influence their adolescent children (Portes, Fernandez-Kelly, \& Haller, 2009). Parenting practices employed by immigrant parents have been recognized as a significant factor that affects their children's functioning: parental strictness and monitoring were found to be associated with lower sexual risk (Killoren \& Deutsch, 2014) and greater academic success (Liew, Kwok, Chang, Chang, \& Yeh, 2014) for immigrant adolescents, especially when counterbalanced by autonomy support. Harsh parenting was related to immigrant children's emotional and behavioral problems (Belhadj Kouider, Koglin, \& Petermann, 2014), while a low level of parental monitoring and parent-adolescent communication difficulties were associated with youth alcohol consumption (Walsh, Djalovski, Boniel-Nissim, \& Harel-Fisch, 2014).

An often-mentioned phenomenon in the context of parent-child relationships in immigration is role reversal. This concept describes a situation in which children adopt adult roles before they are physically or emotionally ready to handle them, while their parents behave as though helpless (Kosner, et al., 2014). The greater adaptability of children and adolescents allows them to adjust to a new social environment, embrace new norms and values, and acquire the host language faster than their parents. As a result their role repertoire in the immigrant family is likely to expand (Mirsky \& Prawer, 2003; Ponizovsky, Kurman, \& Roer-Strier, 2012). At the same time, the feelings of loss and bereavement that often accompany immigrant parents' adjustment may impair their ability to meet their children's needs and lead to parent-child role confusion (Mann, 2004).

There are two main types of adult roles that immigrant children may adopt: instrumental roles that involve taking responsibility for functional tasks, and emotional roles that require the child to meet the parent's social-emotional needs (Jurkovic, 1997). In a qualitative study performed on a sample of FSU immigrant adolescents in Israel (Roer-Strier \& Kurman, 2009), multiple roles assumed by them within their families were identified: language broker, family administrator, emotional supporter, and so on.

Most studies in the area of role reversal focus on situations in which an adverse circumstance such as disease or divorce has hindered parental performance and led to role change. Ponizovsky et al. (2012) and Kosner et al. (2014) believe that role reversal in immigrant families is a distinct phenomenon, initiated by the need to deal with practical issues. As such, it may differ from role reversal caused by parental pathology or weakness and need not have an inherently negative impact on the immigrant family. Accordingly, role reversal has been found to have a complex influence on immigrant adolescents' wellbeing and functioning, both negative (e.g., high distress, low self-esteem) and positive (e.g., gaining independence, life-experience) (Kosner, et al., 2014; Oznobishin \& Kurman, 2009; Trickett \& Jones, 2007). Role reversal may be very dramatic for FSU Jewish immigrant children in particular, as they were typically not encouraged to be autonomous in the FSU and were given almost no family responsibilities besides school performance (Roer-Strier \& Kurman, 2009).

Immigrant families with adolescents often face not only the usual complexities of this developmental stage but additional challenges arising from immigration. Although in this situation family can be a source of support for its members, the pressures of immigration may 
impair relations and increase conflict (Dwairy \& Dor, 2009; Mirsky ,2012). While the immigrant adolescent is involved in the process of maturation, the parents struggle to form a new self-identity in the host country. In this context, parents may perceive an adolescent's distancing and striving for autonomy as a threat to their ego integrity (Mann, 2004).

Conflict may stem as well from cultural differences between parents and youths. Immigrant family members live in two cultures: the ethnic-heritage culture and the new culture of the host society. Since these cultures may not endorse identical values and may not allow adolescents to pursue the same behavioral patterns, immigrant families may experience substantial intergenerational differences and high levels of intergenerational disagreement and conflict (Kwak, 2003; Mirsky, 2012). Rigid adherence to old values on the part of the parents may undermine their parental authority and leave youth without effective adult protection, guidance, or support (Mirsky ,2012).

In general, immigrant parents' adaptation is closely connected to parenting styles characteristic of their culture of origin. According to Roer-Strier and Rosenthal (2001), parents hold an image of the "adaptive adult" that reflects their ideal representation of how their children should be as adults, and they organize their child-rearing practices accordingly. This image is influenced by the parents' culture of origin and undergoes adaptations during immigration. Usually, the image of the adaptive adult held by immigrant parents has aspects that are considered adaptive in their country of origin, as well as aspects they perceive as probably adaptive in the host society.

There is a broad literature that examines parent-child relationships in the context of immigration, generally emphasizing the effects of these relationships on immigrant children's social and psychological adjustment. However, studies that focus mainly on immigrant parents and their own experiences are surprisingly scarce. Immigrant parents experience a variety of adjustment stresses and are exposed to new and unfamiliar parental tasks, while having limited social support. This may challenge their ability to cope with tasks of parenting, increase their distress, and reduce their self-esteem and functioning. Immigrant parents' adjustment takes place in the context of raising children in a new cultural environment. Given the great importance of the parental role in the individual's life, believing in one's own ability to be a successful parent is necessary to normal adjustment. Costigan and Koryzma (2012) found immigrant parents' parental efficacy (the belief in their ability to be competent parents) to be significantly correlated with their psychological adjustment.

\section{Immigrant Families from the FSU in Israel}

As a rule, immigrant families from the FSU are small, with one or two children. Partially for this reason, parents stress the importance of education and invest effort and resources in their children's studies (Yakhnich, 2010). The importance of children's education is also related to the nature of Jewish identity in the FSU, characterized by academic education as a central component (Lerner, Rapoport, \& Lomsky-Feder, 2007).

Despite their general rejection of the Soviet regime, as well as major social changes taking place in the FSU, the majority of immigrant parents were raised and socialized mainly according to collectivist norms. Traditional Soviet pedagogy encouraged child-rearing methods designed to foster such values as obedience and group-mindedness. Violation of these values could justify punishments in the form of parental withdrawal of love and privileges (Shor, 1999). 
In a study focused on FSU immigrant parents' patterns of handling children's misbehavior, it was found that the most common option suggested by the respondents was talking to the child. The most common disciplinary method was setting restrictions, including isolating and ignoring the child. The frequency of respondents who suggested verbal threatening and corporal punishment was low (Shor, 2000). However, in his earlier study, Shor (1999) reported that corporal punishment was found to be an acceptable disciplinary method among FSU immigrant parents, and that there was a high level of agreement about which methods were appropriate. Shor also found that conditional love was viewed as a suitable educational method; for example, parents would withdraw their affection from a misbehaving child.

The image of the adaptive adult among FSU parents often includes such characteristics as self-discipline, conformism, personal modesty, diligence, and academic excellence (Yakhnich, 2010). Accordingly, the parent's role is perceived as authoritative (and sometimes as authoritarian), educative, and didactic; it includes responsibility both for setting clear norms of behavior and for enforcing them. Although immigrant parents tend to maintain the adaptive adult image and the parental role accepted in their culture of origin, in time they may adopt new roles and images as a result of their interaction with the host society (Strier \& Roer-Strier, 2005). This can result in undesirable changes in patterns of parenting, such as an abrupt transition from an authoritarian parenting approach to a highly permissive one. Such sudden transitions may leave the child confused, undermine the parent's authority, and reduce parental involvement and supervision (Yakhnich \& Teichman, 2015).

During adolescence, FSU parents usually expect to maintain close relationships with their children, while limiting their independence and exercising a high level of parental control. Parent-adolescent relationships are often characterized by high involvement, protectiveness, and demands for obedience and self-restraint (Leipzig, 2006; Slonim-Nevo, Shraga, \& Mirsky, 1999). Dwairy and Dor (2009) argue that the gap between the FSU immigrants' parenting style and the permissive character of Israeli society in general may create difficulties for their adolescent children.

Immigrant family relations might be challenged by losing the support of grandparents that stayed in the FSU (Kosner et al., 2014). Families in Eastern Europe (including the FSU) traditionally relied heavily on help from grandparents who often took responsibility for dayto-day childcare (Nesteruk \& Marks, 2009). Maintaining significant intergenerational connections is very important for immigrant parents from this region. However, geographic distance significantly challenges this goal, and parents have to become more independent and self-reliant. In spite of technological advances in communication and travel (Nesteruk \& Marks, 2009; Saxena \& Sanders, 2009) immigrant parents struggle to keep their extended families physically and emotionally close.

\section{Present study}

In this study I aimed to examine FSU immigrants' parenting experiences in the context of cultural transition. The majority of studies that examine the influence of immigration on parent-child relationships emphasize the effect of these relationships on immigrant children's adjustment, while studies that focus mainly on immigrant parents and their own experiences are relatively scarce. Understanding the experiences of parents is crucial to understanding the experiences of their children, especially in immigrant families where so much of the adjustment and functioning of children is involved with their parents' adjustment (Crosnoe \& Filigni, 2012). Creswell (2007) believes that qualitative methodology is best for describing, exploring, and understanding a participant's subjective experience in its real-life context. In this study using qualitative methodology seems appropriate, as it can shed 
light on parents' life experiences and help the reader empathically share them, as well as reveal new data that were not assessed by previous quantitative research (Roer-Strier \& Kurman, 2009). Furthermore, qualitative methodology is claimed to be especially valuable in studies examining culturally embedded issues (Cui, 2015). Using qualitative methodology in this study will allow a deeper understanding of immigrant parents' realities and promote the ability to design prevention and intervention activities for the benefit of immigrant families.

\section{Method}

This is a qualitative phenomenological study that "describes the meaning for several individuals of their lived experiences of a phenomenon and reduces these experiences to a description of their universal essence" (Creswell, 2007, p. 57). The aim of this study is to describe the meaning of the parenting experience in cultural transition.

\section{Participants}

Seventeen parents (14 mothers and 3 fathers) of children aged 11 to 17 participated in the study. The participants ranged in age from 32 to 47. All came from different families: no couples were included. The majority were married, but three were divorced, one was single, and one was a widower. All had either one or two children, except for one who was the mother of three. All participants had immigrated from the FSU (seven from Russia, four from Ukraine, two from Belarus, three from Central Asia, and one from Latvia) and had been living in Israel between one and a half and five years. Their main reason for immigrating was concern for their children's future in their countries of origin, while additional factors such as economic difficulties, political instability, and family reunification were also mentioned. All but three had left their parents in the FSU. Ten had academic degrees, but most were employed in blue-collar jobs after immigration. The majority perceived these jobs as temporary, and hoped to find better positions in the future. The participants mostly described their socio-economic status as middle-low, though more than half estimated their economic situation to have improved after immigration. All but two struggled with language difficulties and felt unable to sufficiently communicate in Hebrew: their close social networks consisted solely of Russian-speaking immigrants.

As mentioned above, three fathers participated in the study. They were generally less verbally forthcoming than the mothers; they used shorter sentences and fewer examples, resulting in shorter interviews. Yet, their level of participation and the issues they raised didn't differ from those of the mothers.

\section{Procedures}

I approached local representatives of the Ministry of Immigrant Absorption in two northern cities and asked their help in locating immigrant parents of adolescent children aged 11 to 17 who had immigrated from the FSU during the last five years. The representatives contacted the parents and asked permission to pass their names on to me. Having received this initial agreement I telephoned the parents to introduce myself and the aim of the study. Dates for interviews were set with the parents who agreed to participate (17 out of the 23 parents initially contacted). The interviews were held at participants' homes at a time that was convenient for them.

The in-depth open interview technique was used (Kvale, 1996). The means to access a subject's experiences range widely, from open-ended, unstructured approaches to highly structured protocols with preset questions. The open interview is a relatively unstructured 
approach applied in ethnography, grounded theory, and phenomenology that may use an evolving set of questions, such that later participants may respond to quite different queries from those put to earlier participants (Knox \& Burkard, 2009). Sometimes only a first, topicintroducing question is asked and the remainder of the interview proceeds as a follow-up and expansion on the interviewee's answer to the first questions. Such an approach is more concerned with being attuned to the participant than with necessarily following the same path for all respondents (Kvale, 1996). The interviews started by presenting the aim of the study and assuring the interviewees of anonymity. Participants were invited to talk about their families in the context of immigration ("Please, tell me about your family's decision to come to Israel."). This was the starting point of all interviews, and the interviewees themselves chose how to continue the conversation. When they finished their stories, if necessary, they were asked to delve deeper into their relationships with their children and their parenting experience. I didn't use preset questions, but attempted to address particular issues: the participants' perception of parenting, the way this perception was affected by immigration, parent-child relationships after immigration, parent's coping with a changed way of life, and so forth. Interviews were conducted in Russian (the participants' and my own native language) and lasted from 50 to 120 minutes. All interviews were recorded and later transcribed. Field notes were written during the interviews and later incorporated into the data. Interviews were held until saturation had been achieved: from about the twelfth interview on, the central themes raised by the participants kept recurring, indicating that the themes were authentic to parenting experience in immigration (Creswell, 2007).

All participants were informed as to the voluntary nature of the study. Their personal information remained confidential and was not disclosed to the representatives who initially contacted them. Each interview was given a serial number. Thus, the participants' names didn’t appear in the transcripts. The names and the numbers were kept in a separate document, assuring the interviewees' anonymity.

\section{Data analysis}

The data were read and reread several times. During the first reading I identified "significant statements" that could enhance my understanding of the participants' experience of their parenting during immigration, a process Moustakas called "horizontalization” (1994). These statements were grouped into clusters of meaning, such as "The parent believes that involvement is a key component of parenting", and "The parent feels that not knowing Hebrew damages her ability to exercise parental control”. These clusters were then reorganized, while identifying the central themes that emerged from the interviews. For example, the theme of "perception of the parental role" was composed of subthemes of "education towards discipline", "parental control”, and more. The subtheme of "education towards discipline" was further divided into the following components: "the purpose of discipline", "the results of lack of discipline", and "discipline as preparation for adult life". When the list of themes was ready, I reread the interviews to ensure that the statements were properly understood and that no significant statements were left out. The themes served as a basis for describing parenting experience in immigration, while identifying common experiences (the essential structure) and creating a cohesive story (Creswell, 2007). In my writing I used the technique of "constructing a document within a document” (Ayalon \& Sabar Ben-Yehoshua, 2010) using data analysis as an initial draft for the results chapter. In a process of observation and interpretation, I de-emphasized some themes, emphasized others, and drew connections between various themes. Finally, I wrote "the story" based on an integration of the research findings and the available theoretical material. During the analysis I used the original Russian transcripts and then translated the results into English. This way the analysis was not affected by potential translation inaccuracies. 


\section{Credibility}

To measure the performance level of qualitative research, Lincoln and Guba (1985) suggest using the term trustworthiness to replace the concepts of validity, reliability, and generalization used in quantitative research (Shkedi, 2003). Trustworthiness may be achieved by keeping the chain of evidence for each step in the research, analyzing the data in several stages, and writing the final report as a "rich description" using interviewees' quotations (Shkedi, 2003). In this study, I fully documented all the interviews and the context in which they were carried out. All stages of the analysis were documented separately, enabling a return to every stage, as well as to original narrations. The Results section presents the interviewees' perceptions by making extensive use of their own words. The technique of constructing a document within a document contributed to the study's trustworthiness by reducing the gap between the coding process and the writing of the research results (Ayalon \& Sabar Ben-Yehoshua, 2010). Finally, I consulted another experienced qualitative researcher, who served as an external expert, commenting on and analyzing the data and the emerging themes (Creswell, 2007; Lincoln \& Guba, 1985).

My personal background on issues relevant to this study should be addressed. At age 13, I immigrated to Israel from the Soviet Union; I also have children. Thus, I've experienced both the challenges of immigration in adolescence (like the participants' children) and of parenting. During the interviews, as well as in the process of data analysis, I recognized several common issues and concerns that occupied not just the participants but me and my family. I believe my personal background helped the participants to feel more comfortable during the interviews and helped me to better understand and appreciate their experiences. At the same time, I strove at all times to distinguish between their perspectives and perceptions and my own.

\section{Results}

\section{Parental responsibility}

Analysis of the interviews yields a variety of themes related to parent-child relationships. During the interviewing stage, it became apparent that all the participants' stories shared a central theme: parental responsibility. All the participants described the parental role as entailing great responsibility; indeed, the very decision to have children makes the parents responsible for raising and educating them. One of the most meaningful expressions of parental responsibility is the parent's obligation to make decisions affecting the children and their future (Perälä-Littunen \& Böök, 2012). The participants' decision to emigrate to Israel was based on the belief that emigration would ultimately be beneficial for the children. Thus, it not only reflects their parental responsibility but even adds to it, as they feel responsible in turn for the children's post-emigration adjustment. V., a mother of a 14year-old girl, described her feeling of responsibility:

To be a parent is first of all responsibility. If you created a person, you are obliged to create the conditions in which she can grow into a healthy, strong human being. She didn't ask to be born, I have borne her for myself, I have to take responsibility and raise her. Especially since bringing her here was my decision, my responsibility.

The issue of parental responsibility is reflected in the participants' perceptions of the essence of the parental role. Immigration challenges their ability to fulfil their responsibility 
as parents. Their attempts to cope with this challenge are often accompanied by a feeling of helplessness.

\section{Who is the responsible parent: Components of good parenting}

When participants discussed their responsibility as parents, mostly in general terms such as "to raise them well”, I asked them to specify the elements of parental responsibility and the characteristics of a responsible parent. The participants focused on four key components of responsible parenting: control, involvement, discipline, and parental guidance.

Control. "Control is obligatory": One component of parenting mentioned by the interviewees is the need to control what happens in children's lives, including their behavior and their social lives. Control is exercised mainly through communicating with children, expressing interest, and making them understand the importance of involving parents in their lives. Five parents reported that their children resist their efforts to control them, and described how they try to "squeeze out information by all means". To justify the necessity of control, interviewees used examples of parents who have not exercised enough control, which produced negative consequences:

Even if she is angry with me, control is obligatory. I know many parents who start working in five jobs only to earn more, and then ... they don't need this money any more, because the children go off the straight path. I have always known her friends and their families. If Jana goes to sleep over at a friend's house, I always ask: "Who is the father? Who is the mother? Where do they live?” I know everything. (S., mother, children ages: 13, 17).

Control gives parents a sense of mastery, of having "a finger on the pulse", and is perceived as an expression of real interest and concern for the child.

Involvement. "I have to listen": Another component of good parenting is involvement in the child's life, as expressed by the parents' accessibility and readiness to listen. Nine parents spoke of accessibility and listening as a way of meeting their child's emotional needs: "They should turn to me, tell me, and I have to listen, to help. They are still kids, but they have problems that they need to share” (K., mother, 11, 15). These needs are intensified by the child's age: "Adolescents - they have their moods. And I see she needs more attention, she needs me to be more patient with her, she needs someone she can trust" (L., mother, 14); and by loss of social networks during the immigration: "It's very important not to let him become isolated, to be alone with his problems. He has no friends. He doesn't have anyone to talk to, only us” (I., mother, 16).

Five participants who raised the issue of involvement perceived it as an additional means of control: "I teach her: 'The first person you must come to is your mother'. I believe children need to consult their parents first. Only this way will the parents know what's going on with their children” (S., mother, 13, 17).

This perception of listening and closeness to the adolescent as the means of exercising parental control may explain the FSU immigrant adolescents' tendency to report their parents as less warm and more controlling, compared to their Israeli peers (Dwairy \& Dor, 2009).

Discipline. "Life will not caress you": The issue of discipline emerges in most interviews as an area in which no compromises should be allowed. Discipline is perceived as an educational means of preparing the child for adult life, responsibility, and normal functioning: 
Everybody has obligations: mother has to prepare food, keep house, she has to do that, whether she likes it or not. Father has to earn a living, it's his duty. And the child has to get used to her duties from the beginning, gradually.... (O., mother, 12).

Imposing discipline is seen as the parents' responsibility: parents who don't do it are failing in their role. I., mother of an 11-year old daughter, considered lack of discipline to be an essential fault in the process of moral education, one which leads to unwanted developmental outcomes:

There has to be discipline. It is forbidden to let children do whatever they want, so they will grow and become adults who hear only themselves, their own wishes, they will not want to work. Children have to be accustomed to discipline from an early age.

Imposing discipline is based on perceiving adult life as a challenge that children have to be prepared for. Being too spoiled will damage children's ability to cope with life. This perception reflects the life experiences of the parents themselves. V., who had raised her 14year-old daughter alone from birth, said:

Sometimes I think my daughter had no childhood, I never coddled her. I always tell her, "Maybe I am angrier with you than necessary, maybe I should praise you more, but life is hard, it rarely caresses you. Life mostly hits you. That's why.

Parental guidance. "To distinguish between black and white”: Another parental role regarded as important by the participants is parental guidance. Parents are perceived as the people who know their children best and, hence, are able to identify their tendencies and skills. Based on their own life experience, parents can guide children towards desirable directions that suit these tendencies. Guidance is needed in the area of studies, spending leisure time, choosing hobbies, and so on. Without such guidance, children may choose an unwanted course of life: “They don't always know how to choose properly. This is the role of the parents - to guide them to the right path, help them understand what's black and what's white” (O., mother, 12).

If parents do not guide their children, they leave them prey to unwanted influences, as A., mother of a 17-year-old daughter explained: "A child... someone influences her in any case. If not parents, who? Friends are not always suitable, teachers don't always really care. If parents have no influence — children are always influenced by someone else”.

Parents emphasized that their modes of thought should not be forced upon children; instead, the guidance process should be suited to the child's personality and wishes:

They have to find something they want, something that appeals to them, draws them. One should not nag all the time: you have to, you have to ... a child should want to paint a picture, to compose a tune ... if the child doesn't want to, nothing will come out (K., mother, 11, 15).

\section{Difficulties in fulfilling parental responsibility in immigration}

So far I have described the central themes that emerged from the discussions about the parental role. These themes represent some of the universal challenges in parent-adolescent relationships, but at the same time are shaped by the participants' cultural background and reflect their varied personal ideals of the responsible parent. But what happens to this image in cultural transition? Do parents succeed in applying their beliefs about optimal parenting to 
the reality of their present lives? Three central themes emerged in this context as factors influencing immigrant parents' ability to fulfil their parental responsibility: lack of emotional and physical (practical) availability, language difficulties, and cultural gaps in perceptions of child rearing.

Lack of availability. "We have no time for them": Most (13) participants reported being too occupied to pay attention to their children, and that the key factor taking up their time is work. Most of them mentioned that they work many more hours than they used to before immigration and thus have much less time to spend with their children: "The whole life is at work. We have no time for them" (V., father, 12). The limited time available for parents to spend with their children is seen to exact a toll on their relationships. Due to her workload, K. (mother, 11, 15) sensed a growing distance between her and her children. When she tried to initiate common activities, she felt they were not interested: "They forgot how it is to spend time with me. It bothers me”.

The burden imposed on some parents may blind them to their children's emotional difficulties. E. (mother, 17) recalled the moment she found out her daughter had been skipping school for several months:

It was like thunder on a bright day. I couldn't imagine this would happen to my daughter ... in fact, I didn't have time for her. I was working, studying — I had so much to do. Maybe there were moments I didn’t listen to her because I was too busy with my own affairs.

Long working hours, being paid by the hour, a confining organizational culture, and stress make parents' work more demanding and impair their ability to pay attention to their children (Roeters, van der Lippe, \& Kluwer, 2010). Most participants in the study were engaged in non-professional work, earned minimal wages paid on an hourly basis, and were afraid of losing their source of income. Participants who worked in jobs that suited their training were employed mostly in small businesses, and felt dependent on their employers. Economic hardships, together with the kind of work the parents were engaged in, produced stress that constrained their involvement in their children's lives.

In addition to long working hours, the parents reported lack of emotional availability for their children. Adaptation difficulties, language problems, and coping with change diverted their energies and directed their coping efforts away from their children. K. (mother, 11) described the time it took her to pull herself together and be available for her son:

I find it very hard. Only now did I get to him (her son). It turns out he is the last one, at the end. I tried but it didn’t work ... I was not emotionally available, not at all. He demanded so much, I didn't have so much to give. I felt he got into me with a spoon, dug in me, and I had nothing to give him anymore.

K. felt exhausted, empty, and emotionally overwhelmed, which made it hard for her to pay attention and support her son.

Language difficulties and language mediation. “Mom, you better shut up": All parents reported that their children started speaking Hebrew and were able to engage in social interaction sooner than their parents. Most participants (11) said that their children react negatively to their language difficulties. Some children were ashamed when their parents spoke Hebrew: “They tell me: 'Mom, you'd better shut up, don't talk. Mom, you're dumb'. They are ashamed. It's a joke, of course (laughs)" (S., mother, 13, 17). Parents' mistakes in Hebrew made some children become angry and react aggressively: "She yelled at me: 'You 
don’t know how to talk! Say nothing!' She was angry because I didn’t speak correctly”. E. (mother, 17) also laughed as she described her daughter's reaction. A. described the feeling of helplessness when speaking with her 17-year-old son:

He got really upset with me: “Can’t you say a simple thing?” I didn’t know how to answer. Maybe he is used to me having always helped him. Now he sees I am powerless, I don't understand what is wanted from me.

The aggressive and humiliating reactions described above are not characteristic of parent-child relationships accepted in the FSU (Walsh, Shulman, Bar-On, \& Tsur, 2006). Moreover, they contradict the participants' own perceptions of parenting as presented above. Nevertheless, the participants' tone, laughter, and choice of words in describing children's reactions, suggest an attempt to turn the theme into a joke and belittle its meaning. I felt that being perceived by their children as weak, incapable, or "dumb" hurts the parents and sets a new challenge for which they had developed no other coping mechanism.

Some children helped their parents with translations. The parents' and children's attitude towards this language mediation was complex. L. described her 14-year-old daughter as a counselor, a defender, and a role-model for her mother:

She says: “Tell me, I'll tell everything instead of you”. She also tells me: "Mom, sit home, learn Hebrew”. She explains to others: "She can’t do it like you, it's hard for her”. Sometimes I feel younger than she is. I listen to her, learn from her.

Four parents felt that their children's help serves as a positive stimulation that strengthens their self-esteem: "I think it makes them very happy — 'I know better than dad'. I think it makes them proud” (A., father, 14, 17). However, in most families the parents' dependence on their children's help led to conflicts, antagonism from the children, and frustration for the parents. V. (mother, 14) described it as follows:

When I ask her for help, she may tell me: “I don’t understand”. And that's it — I am left without an answer: "Please read at least a few words, only so I understand what it is about". Sometimes she yells at me: "Do you know any other kids who do this?” In Russia I didn’t depend on her, there they speak Russian....

A complex picture emerges from the participants' words. Language mediation is perceived as having a potential of strengthening the child, but at the same time of putting him or her in a dominant position in relation to the parent. Language gaps and mediation challenged the parent's influence and responsibility and aroused a wide spectrum of emotional reactions among participants, which led to a reconstruction of parent-child relationships in their families.

\section{Cultural differences in perceptions of child rearing. "There is no such thing in}

Russia": The participants, whose perception of parenting is based largely on control and discipline (as mentioned above), reported experiencing a large gap between this perception and what they deemed to be accepted ways of child rearing in Israel. Most (14) parents portrayed Israeli education as lacking in discipline - "The children here are not really being educated." — and thought more highly of Russian education. They perceived Israeli parents as unable to set limits, compromising, and not guiding their children's choices, as described by A. (mother, 17):

I see young children eat restaurant chips. This is not appropriate food for children, but they eat it. And the mother, instead of taking the plate away, 
indulges him. This is a borderline situation of democracy. There is no such thing in Russia. Maybe it's a bit aggressive, maybe it's a kind of pressure, but judging by the results ...

Judging by results, parents perceived Israeli children's behavior as unacceptable. They noted their lack of respect towards the elderly; unbridled, impulsive behavior; lack of consideration for others; and so on. They said it's easy to identify children of Russian origin by their more polite and restrained behavior.

While most parents clearly prefer familiar ways of child upbringing, four expressed ambivalent attitudes and were able to see advantages and disadvantages in the different educational approaches. E. (mother, 17) demonstrated this ambivalence metaphorically:

Pupils in lower grade classes here write with pencils - they may erase and rewrite. This teaches children not to be afraid of making mistakes in life too. In Russia they write with pens. And if you wrote with a pen, made a mistake and then corrected it, there is a "stain". There they are afraid to make mistakes. Here they feel they can do anything; on the one hand, this is an advantage. They are not afraid to make a step forward. The disadvantage is that everything is allowed. Sometimes it looks like boorishness, kind of permissiveness. They believe they are allowed everything. They don’t accept “no” for an answer.

Participants felt that their children had begun to absorb influences from the Israeli environment. The principal change occurred in the areas of discipline and respect for adults' authority: "The first thing she learned here: 'It's a free country. I do what I want.'” (A., father, 14, 17). Participants reported that their children now spoke less respectfully, disregarded parents' authority, argued, did not comply immediately with their demands, and so forth. These changes often led to conflicts between parents and their adolescent children as well as to confusion and a sense of helplessness among the parents.

\section{Coping with children's changing behavior}

Children's faster adjustment often creates cultural gaps between them and their parents, thus enhancing intergenerational conflict. The conflict is expressed in changing intergenerational boundaries, undermining of parental authority, and the parents' fears of losing the child to the new culture and of change in general (Baptiste, 1993; Walsh et. al., 2006). Research participants chose to cope with change mainly by attempting to preserve traditional ways of education. Four parents expected their children to go on behaving in the way accepted in the FSU, even at the expense of their social integration:

When we saw the local children, the first thing my husband said: "Our children should not become like that”. I want them to grow with certain principles, even if they will be different from other children — at least we won't be ashamed of them (I., mother, 16).

One way of maintaining behavior patterns prevalent in the FSU is encouraging social contacts with Russian-speaking peers. These contacts are perceived as a means of learning "normal" behavior and a defense against unwanted influences. Some parents were simply satisfied with the fact that their children had "Russian" friends, while others initiated and guided their children in shaping their social networks, like V. (mother, 16): "When she goes out with her girlfriends, I always tell her: 'Take S.' I want her to have this kind of influence”. 
Another way parents tried to maintain authority and traditional education was persuasion, ranging from attempting to explain their demands to open conflict and coercive use of their parental power. $\mathrm{N}$. (father, 12) described the range of his reactions when his sons did not obey him:

There, I used to tell them once and that was it, everything was done. And here "we don't want to, wait, later". Like a dead end. I explain: "We are parents, we know what's right. When you grow up, you'll live your own way. Now, you do this and that”. It doesn't work. Then I raise my voice, I'm angry. So far we have overcome this; I don't know what will happen later on. I'm afraid it will be problematic.

N. immigrated to Israel one and a half years ago and understood that his way of managing conflict with his children would lose its efficacy in the future, but he had no other tools to cope with the change. Six other parents who were more experienced in parenting in cultural transition understood that in order to cope with the new situation they had to undergo a change too, but found it hard, like L. (mother, 17):

I was told I have to change, there it was different - here it's something else. One should learn to look differently at things. I think I will not succeed in looking at things differently. I take it close to heart, I get irritated. I don’t know what will be.

A feeling of uncertainty about the future emerged from N. and L.'s words. Neither could foresee how they would cope with the expected changes in their children's behavior. They are not alone in this experience. Problems of erosion of parental authority and discipline are often mentioned in studies dealing with parenting in immigration (Nesteruk \& Marks, 2011; Strier \& Roer-Strier, 2005). Immigrant parents from Asia, Eastern Europe, and South America often report difficulties in educating their children given what they see as eroded obedience and respect towards adults in Western countries. In this study, the loss of parental authority and the lack of tools for effectively coping with children's changing behavior aroused in some parents a feeling of helplessness: “I don't know what to do, but I can’t just do nothing. This is my daughter, it is my responsibility, but I don't know what to do" (E., mother, 17).

The issue of parental responsibility emerged again, but in the context of the difficulty in fulfilling it and being a responsible parent. Three parents admitted to having agreed to the interviews in order to allow themselves to think aloud about what's happening to them: "This is why I agreed to participate in the study — I wanted to open this chapter of my life. Because from the minute I arrived here until today, I have tried not to analyze it” (K., mother, 11). About half of the parents asked me for direct advice about the right ways of coping or tried to find out about the help they can get to cope with their parenting difficulties:

When we spoke on the phone, I immediately thought about asking you, maybe it is possible to talk to someone professional? Sometimes it's hard, I don't understand, don't know, I don't have enough tools. Maybe there is a program for children, someone to talk to them... (K., mother 11, 15).

Most participants felt that they did not know how to deal with the parental challenges they faced. They realized that educational methods based solely on control and discipline have limitations in their present reality. Even those who found no fault with such methods understood that they needed to change in order to maintain a good relationship with their children, but they didn't know how to bring about the change, or whether they would be able to do so. However, only half of the parents raised the possibility of getting professional help 
in coping with these challenges, and only one admitted to having already sought it. It should be noted that participants who asked for advice or expressed interest in getting help were provided with information on relevant services available in their community.

\section{Discussion}

The aim of this study is to examine FSU immigrants' parenting experiences in the context of immigration and cultural transition. The findings are based on 17 in-depth open interviews with immigrant parents of adolescent children. Adolescence represents an important phase in the individual's development that involves a broad range of physical, emotional, and cognitive changes. These changes have significant impact on parentadolescent relationships (Babore, Picconi, Candelori, \& Trumello, 2013). As adolescents mature and seek autonomy, they increasingly challenge their parents' decisions and authority. Accordingly, conflict between adolescents and their parents is a common phenomenon that is generally considered to serve an adaptive role in family relationships (Moed et al,. 2014). Disagreements between parents and adolescents are thus to be expected during this developmental stage, creating many challenges that may not be specifically immigrationrelated. However, the difficulties presented in this study were perceived by the participants as resulting particularly from the immigration and adaptation experiences coupled with challenges of adolescence, and not from the adolescence phase itself.

During the interviews several themes essential to the participants' parental experience emerged: parental responsibility and its components, difficulty in fulfilling parental responsibility in immigration, and feelings of helplessness and uncertainty that accompany the need to cope with children's changing behavior.

The participants' perception of parenting was largely based on the concept of parental responsibility. This responsibility generally serves as the emotional glue in parent-child relationships (Perälä-Littunen \& Böök, 2012). It is further strengthened during immigration, when parents feel that bringing their children to Israel makes them responsible for their adaptation and functioning. The participants' perception of parental responsibility was based on four components: control, involvement, discipline, and guidance. These elements point to participants' preference for an authoritative-authoritarian parenting style (Baumrind, 1978): statements regarding behavior control, education towards self-discipline, and guiding children's choices clearly emphasize the control component. Parental involvement through listening, as well as attentiveness to the child's wishes and personal characteristics, point to the importance of the acceptance component in participants' parenting.

The literature consistently points out the advantages of authoritative parenting compared to other styles (Kudo et al., 2012; Rinaldi \& Howe, 2012). The authoritarian style, in contrast, is negatively viewed in Western literature due to its correlation with such traits as lack of self-responsibility, low self-esteem, and extreme obedience (Sartaj \& Aslam, 2010). However, there are researchers who claim that the effectiveness of a parenting style depends on the cultural context in which the family lives, and in some cultures children may enjoy optimal developmental outcomes due to other, non-authoritative parenting styles (Dwairy, 2004; Garcia \& Garcia, 2009). The participants' tendency to form a parenting style that ranges between authoritative and authoritarian is compatible with their cultural background, and their perception that normative parenting in the FSU entails full parental authority (Slonim-Nevo et al., 1999; Walsh et al., 2006). Yet the encounter between this parenting style and the child-rearing practices prevalent in Israel confronts the participants with complex challenges and the need to revise their way of thinking about parenting. It should be 
remembered, however, that most of the youth in the study were preadolescent when they lived in the FSU, thus the parents' preference for a particular parenting style may be affected not only by cultural background, but by children's maturation as well.

After immigrating to Israel, parents find it difficult to fulfil their parental responsibility. Due to long working hours, they lack time to pay attention to their children (Roeters et al., 2010), and the adjustment hardships they encounter often leave them emotionally unavailable to their children. These factors have a detrimental effect on their parenting. Many parents report that their enforced lack of availability leads to distancing on the part of the children, and a feeling of missing out for the parents themselves. It is possible that the participants' tendency toward authoritarian child-rearing practices is partially a product of their new reality, as their exhaustion and overload don't leave much space and patience for parental acceptance, nor for exploration of alternative approaches.

Another factor that tests participants' parental responsibility is language difficulties. These difficulties cause shame and anger in some children, expressed in verbal aggressiveness towards the parents. Some participants tend to belittle the meaning of the phenomenon and relate to it with humor. Humor helps to reframe uncontrollable events and promotes coping with the stress that accompanies them (Folkman, Lazarus, Pimley \& Novacek, 1987). In conflict situations humor can temper and even end the conflict (Norrick \& Spitz, 2010). Many parents feel powerless in situations that challenge their Hebrew language skills, and their children's reactions sharpen that feeling. Relating to the events described in a humoristic manner makes them seem less serious and diminishes their threat to the parents' authority.

Many parents report that children help them with translations. Immigrant children often become language brokers for their families, translating the new language when needed (Jones \& Trickett, 2005). This brokering usually includes the interpretation of cultural norms and practices, so that children become cultural mediators as well. Some participants perceive language mediation as a positive factor strengthening the self-esteem of the child, while others perceive it as a negative factor that increases their feeling of helplessness and dependence on children. Language brokering has been considered a stressor and a burden for an immigrant child, but at the same time as a factor having a variety of cognitive, emotional, and social benefits (Ponizovsky et al., 2012). Some studies describe the advantage of language mediation in terms of high academic achievement (Acoach \& Web, 2004), selfconfidence (Buriel, Perez, de Ment, Chavez, \& Moran, 1998), cooperation with family members, and closeness to parents (Dorner, Orellana \& Jiménez, 2008). Other studies point to high levels of depression, anxiety, and somatic complaints among mediating children (Weisskirch \& Alva, 2002), and low self-esteem and confrontations with parents concerning mediation (Oznobishin \& Kurman, 2009). Interviews yielded a complex picture in which language mediation is perceived as possibly benefiting the child but also as raising his or her status at the parents' expense. The rather negative experience related to language brokering that was found in this study may be explained by cultural characteristics of parenting. As noted above, the participants mostly preferred an authoritative-authoritarian parenting style. Language brokering may increase children's dominance in their relationships with their parents, thus impairing immigrant parents’ authority (Oznobishin \& Kurman, 2009).

Another factor relating to parental responsibility that caused difficulty for the participants was the cultural gap between their perception of child rearing in their culture of origin and their perception of child rearing in Israel. The parents experience Israeli childrearing practices as setting no limits, encouraging inconsiderate behavior, and turning parents into passive people who give in to their children's caprices. The participants' children, after 
being exposed to the educational perceptions prevalent in Israel, tend to adopt unacceptable behavior patterns. Parents are especially troubled by behaviors that lead to disparaging their authority and eroding discipline.

Cultural transition challenges immigrant parents' parenting perceptions and requires them to engage in continuous cultural negotiation in which some traditional parenting components will disappear, some will be maintained, and some will be reinforced from generation to generation (Choi, Kim, Pekelnicky, \& Kim, 2013). Participants describe a complex process in which they try to find a balance between their perception of parenting and education and the demands of their new reality. Most of them try to maintain traditional education patterns (authoritative-authoritarian parenting), even at the expense of the child feeling conspicuous or out-of-place among peers. Preservation efforts are expressed in the participants' strict following of cultural components of parental responsibility, such as discipline and control, maintaining rules of behavior that were prevalent before immigration, and encouraging social contacts with children who speak Russian.

Many parents understand that in order to maintain a close relationship with their children, they will have to change, but experience this change as threatening and are not sure whether they will be able to accomplish it. These experiences arouse feelings of uncertainty and helplessness in some parents, thus undermining their sense of parental efficacy. Parental efficacy is defined as one's estimation of one's ability to be a competent and successful parent (Coleman \& Karraker, 2003). It is a focal component of parenting and is connected to a general sense of self-efficacy and positive affect (Coleman \& Karraker, 2003) as well as to supportive parenting and limited use of inefficient disciplinary means (Slagt, Deković, De Haan, Van den Akker, \& Prinzie, 2012).

In order to cope with feelings of helplessness and undermined parental efficacy, some participants considered the possibility of getting professional help. Some parents turned to me during the interviews with direct requests to advise them on appropriate ways of coping, or asked whether there were professional services that could help them and their children. Only one mother had already sought professional help concerning relations with her adolescent daughter. In spite of feeling helpless and uncertain, most interviewees did not mention at all the possibility of getting professional help. FSU immigrants' reluctance to turn to psychosocial services is generally attributed to a basic difference between such services in FSU and in Western countries, lack of trust in the establishment, fear of stigma, and so forth (Leipzig, 2006). As a result, immigrant parents who experience difficulties in relations with their children are left alone with their problems and try to cope with the means at their disposal, means that are often limited and unsatisfactory due to the lack of availability, language difficulties, cultural gaps, and other problems.

The participants tended to report mostly negative effects of immigration on their parenting. Only two parents reported that there had been a positive shift in their relations with their adolescents following immigration; both perceived this shift as resulting from changes in the family structure after arriving in Israel (distancing from over-involved grandparents and getting support from the extended family). These findings support the notion that immigrant families may experience more difficult intergenerational relations due to greater cultural distance between the adolescents and their parents, as compared to non-immigrant families (Kwak, 2003). Crosnoe and Fuligni (2012) point out that historically it was believed that immigrant children and their families were found to be struggling on many key indicators of wellbeing; however, several recent studies suggest that, despite the many obstacles, immigrant children and families are in fact doing better than native-born children and 
families. While the extant literature provides evidence for both perspectives (Crosnoe \& Fuligni, 2012), this study supports the former.

The study was conducted in the Israeli social context and based on interviews with immigrant parents from the FSU. Some of the findings are unquestionably specific to the Israeli-Russian cultural encounter (e.g., perception of effective parenting, specific childrearing practices, willingness to get professional help). However, its insights are highly relevant to those who work with immigrant families in other immigration-receiving countries. Despite the diversity of immigrant populations, and of hosting societies, immigrant parents around the world encounter many common challenges and experiences (Turney \& Kao, 2009). The parental image of the adaptive adult, as well as child-rearing practices that are significantly influenced by the parents' culture, undergo substantial changes during immigration (Roer-Strier \& Rosenthal, 2001). The parenting style that was formed in the country of origin and was practised in the family until immigration may come in conflict with parenting practices accepted in the new country, creating intergenerational difficulties for immigrant parents and their adolescent children. Immigrant adolescents' exposure to different and sometimes conflicting norms and values by various socialization agents (e.g., school, parents) may impair their school functioning (Chandler, Argyris, Barnes, Goodman, \& Snow, 1986) and even lead to inconsistency in value priorities across distinct life contexts (Daniel et al., 2012). As to immigrant parents, cultural differences in parenting confront them with complex challenges in fulfilling their parental responsibility as they perceive it. The conflict is further intensified by parents' adaptation difficulties that make them less available for their children, and language deficiency that puts them in need of children's language mediation (Jones \& Trickett, 2005), as well as by changes in children's behavior following immigration. The parents are engaged in a continuous process of cultural negotiation and change (Choi et al., 2013) that may threaten and undermine their sense of parental efficacy (Coleman \& Karraker, 2003).

This study supports already existing knowledge on immigrant families' adaptation with regard to such issues as cultural differences in parenting practices, loss of parental authority, and parent-child cultural distance. Its unique contribution lies in recognizing the significance of parental responsibility as a crucial factor in immigrant parents' adaptation, refining its key elements and culture-specific characteristics, and documenting the challenges faced by parents while struggling to fulfil their responsibility in cultural transition. The study illustrates the conflict between the "old" and the "new" induced by exposure to new social norms and by inevitable changes in youth's behavior, and demonstrates how this conflict is experienced by the parents and impacts their sense of parental efficacy and wellbeing. A significant advantage of this study is its phenomenological nature that allows for in-depth and empathic understanding of immigrant parents' reality.

\section{Summary}

FSU immigrants constitute a large minority group in Israel (17\% of the Israeli population). As a result, public social and educational services stress the development of culturally-appropriate intervention practices, including the employment of Russian-speaking professionals, in order to address the needs of this population. The Israeli Ministry of Education operates a variety of programs aimed at promoting immigrant students' integration into the education system, and provides their families with mediation and translation services and counseling (Israeli Ministry of Education, 2013). The Israeli Anti-Drug Authority organizes parents' groups for Russian-speaking parents with an emphasis on developing parenting skills and preventing risk-taking behaviors (Israeli Anti-Drug Authority, 2008). 
Immigrant parents' needs are also addressed by social and psychological services at the municipal level. As well, help and support are offered to newcomers by non-profit immigrants' organizations, such as the Immigrant Parents Forum association that operates the Family Assistance Program. This program provides guidance for immigrant parents whose adolescent children are involved in crime (Yakhnich \& Teichman, 2015). Service providers and professionals working with immigrant parents, both in the public sector and through ethnic associations, should consider the issues that have emerged in this study. Most importantly, immigrant parents in need should be identified as early as possible, since most of them will not spontaneously ask for help. The assistance, whether administered individually or in groups, should focus on increasing flexibility in immigrants' parenting styles according to changes occurring in their children's behavior. This may be done through activities aimed at raising parents' awareness of their parenting styles, discussing the advantages and disadvantages of existing styles in dealing with children's behavior, and helping to adapt their parenting to families' contemporary needs. Parallel sessions that assist the youth in understanding their parents, as well as joint parent-adolescent meetings, may be highly helpful.

Early intervention may prepare parents for future changes and reduce their sense of helplessness. Supporting immigrant parents and meeting their emotional needs may lessen their sense of being overwhelmed and make them more available to their children. Service providers should help distressed parents to clarify priorities and organize their time, while raising their awareness of children's needs and emphasizing the importance of parental involvement. Helping parents overcome language difficulties may reduce their dependence on children's language mediation, thus strengthening parental status and authority.

Finally, child protection services should be aware of the conflicts and challenges facing immigrant parents. Parental exhaustion, confusion, and a sense of helplessness may increase the likelihood of child neglect and abuse.

\section{Limitations and future directions}

This study has certain limitations. First, the study sample was relatively small, and only parents who gave their consent participated in the study. The experiences of the parents who refused to be interviewed may have been different, possibly even more complex and difficult. Their refusal may have stemmed from not wishing to talk about issues that raise feelings of frustration. Therefore any generalizations need to be made carefully. Second, the participants vary in the length of time they have lived in Israel from one and a half to five years. I felt that parents with longer residencies had had more opportunities to reflect on parenting in immigration: their children had undergone more thorough socialization in Israeli society and the gap between children and parents was greater. Future studies should narrow the range of residence duration in the host country, and provide information about the social, cultural, and economic conditions faced by the participants. This will enable the researchers to focus on a more homogeneous sample. The third limitation is that only a few fathers participated in the study. The couples I contacted decided for themselves which parent would be interviewed, and most chose the mother. There was no difference in fathers' and mothers' level of participation or in the issues they raised; however, future research should focus on each group separately. Finally, as a large part of immigrant adolescents' adaptation takes place within the educational system, it would also be of interest to explore the connection between parenting and adolescents' school experience. 


\section{References}

Acoach, C. L., \& Webb, L. M. (2004). The influence of language brokering on Hispanic teenagers' acculturation, academic performance, and nonverbal decoding skills: A preliminary study. Howard Journal of Communication, 15, 1-19.

Ayalon, Y., \& Sabar Ben-Yehoshua, N. (2010). The process of content analysis according to grounded theory. In L. Kacen \& M. Krumer-Nevo (Eds.), Qualitative Data Analysis, pp. 359-382. Beer Sheva, Israel: Ben-Gurion University Press.

Babore, A., Picconi, L., Candelori, C., \& Trumello, C. (2013). The emotional relationship with parents: A validation study of the LEAP among Italian adolescents. European Journal of Developmental Psychology, 11, 728-739.

Baptiste, D. A. (1993). Immigrant families, adolescents and acculturation: Insights for therapists. Marriage and Family Review, 19, 341-363.

Baumrind, D. (1978). Parental disciplinary patterns and social competence in children. Youth and Society, 9, 239-276.

Belhadj Kouider, E., Koglin, U., \& Petermann, F. (2014). Emotional and behavioral problems in migrant children and adolescents in Europe: A systematic review. European Child \& Adolescent Psychiatry, 23(6), 373-391.

Bhargava, S., \& Witherspoon, D. P. (2015). Parental involvement across middle and high school: Exploring contributions of individual and neighborhood characteristics. Journal of Youth and Adolescence, 44, 1702-1719.

Browne, D. T., Meunier, J. C., O’Connor, T. G., \& Jenkins, J. M. (2012). The role of parental personality traits in differential parenting. Journal of Family Psychology, 26, $542-553$.

Buriel, R., Perez, W., de Ment, T., Chavez, D., \& Moran, V. (1998). The relationship of language brokering to academic performance, biculturalism, and self-efficacy among Latino adolescents. Hispanic Journal of Behavioral Sciences, 20, 283-297.

Chandler, J., Argyris, D., Barnes, W. S., Goodman, I. F., \& Snow, C. E. (1986). Parents as teachers: Observations of low-income parents and children. In B. B. Schieffelin \& P. Gilmore (Eds.), The acquisition of literacy: Ethnographic perspectives (pp. 171-187). Norwood, NJ: Ablex.

Choi, Y., Kim, Y. S., Pekelnicky, D. D., \& Kim, H. J. (2013). Preservation and modification of culture in family socialization: Development of parenting measures for Korean immigrant families. Asian American Journal of Psychology, 4(2), 143-154.

Cohen, E. (2007). Parental coping and parental care. In E. Cohen (Ed.), The parenthood experience: Relationships, coping and development, (pp. 9-38). Jerusalem: Ach.

Coleman, P., \& Karraker, K. H. (2003). Maternal self-efficacy beliefs, competence in parenting, and toddlers' behavior and developmental status. Infant Mental Health Journal, 24(2), 126-148.

Collins, A. W. \& Laursen, B. (2004). Changing relationships, changing youth: Interpersonal contexts of adolescent development. The Journal of Early Adolescence, 24(1), 55-62. 
International Journal of Child, Youth and Family Studies (2016) 7(1): 1-26

Cosher, H., Ben-Arie, A., \& Cohen, S. (2011). Immigrant children in Israel 2011. Jerusalem: The Israel National Council for the Child.

Costigan, C. L., \& Koryzma, C. M. (2011). Acculturation and adjustment among immigrant Chinese parents: Mediating role of parenting efficacy. Journal of Counseling Psychology, 58(2), 183-196.

Creswell, J. W. (2007). Qualitative Inquiry and Research Design: Choosing Among Five Traditions (2nd ed.). Thousand Oaks, CA: Sage Publications.

Crosnoe, R., \& Fuligni, A. J. (2012). Children from immigrant families: Introduction to the special section. Child Development, 83(5), 1471-1476.

Cui, K. (2015). The insider-outsider role of a Chinese researcher doing fieldwork in China: The implications of cultural context. Qualitative Social Work: Research and Practice, 14(3), 356-369.

Daniel, E., Schiefer, D., Möllering, A., Benish-Weisman, M., Boehnke, K., \& Knafo, A. (2012). Value differentiation in adolescence: The role of age and cultural complexity. Child Development, 83, 322-336.

Davies, M. (Ed.). (2000). The Blackwell Encyclopedia of Social Work (p. 245). UK: WileyBlackwell.

Dorner, L. M., Orellana, M. F, \& Jiménez, R. (2008). "It’s one of those things that you do to help the family": Language brokering and the development of immigrant adolescents. Journal of Adolescent Research, 23, 515-543.

Dwairy, M. (2004). Parenting styles and mental health of Palestinian-Arab adolescents in Israel. Transcultural Psychiatry, 41, 233-252.

Dwairy, M., \& Dor, A. (2009). Parenting and psychological adjustment of adolescent immigrants in Israel. Journal of Family Psychology, 23, 416-425.

Edelstein, A., \& Bar-Hamburger, R. (2007). Substance use and related delinquency among former Russian youth in Israel. Jerusalem: National Anti-Drug Authority of Israel.

Ehrlich, K. B., Hoyt, T., Sumner, J. A., McDade, T. W, \& Adam, E. K. (2015). Quality of relationships with parents and friends in adolescence predicts metabolic risk in young adulthood. Health Psychology, 34(9), 896-904.

Farmer, A. Y., \& Lee, S. K. (2011). The effects of parenting stress, perceived mastery, and maternal depression on parent-child interaction. Journal of Social Service Research, 37, 516-525.

Folkman, S., Lazarus, R. S., Pimley, S., \& Novacek, J. (1987). Age differences in stress and coping process. Psychology and Aging, 2, 171-184.

Galatzer-Levy, I. R., Mazursky, H., Mancini, A. D., \& Bonanno, G. A. (2011). What we don't expect when expecting: Evidence for heterogeneity in subjective well-being in response to parenthood. Journal of Family Psychology, 25, 384-392.

Garcia, F., \& Garcia, E. (2009). Is always authoritative the optimum parenting style? Evidence from Spanish families. Adolescence, 44, 101-131. 
International Journal of Child, Youth and Family Studies (2016) 7(1): 1-26

Horenczyk, G., \& Ben-Shalom, U. (2006). Acculturation in Israel. In D. L. Sam \& J. W. Berry (Eds.), The Cambridge Handbook of Acculturation Psychology (pp. 294-310). Cambridge, UK: Cambridge University Press.

Horowitz, T., \& Brosh, T. (2011). Patterns of drug and alcohol abuse among youth from the Former Soviet Union. Jerusalem: The Henrietta Szold Institute.

Israeli Anti-Drug Authority. (2008). Evaluation of immigrant parent groups for the Israeli Anti-Drug Authority. Jerusalem: Author.

Israeli Ministry of Education. (2013). Immigrant pupils absorption department. Retrieved October, 2013 from http://cms.education.gov.il/EducationCMS/Units/olim

Jokela, M., Kivimaki, M., Elovainio, M., \& Keltikangas-Jarvinen, L. (2009). Personality and having children: A two-way relationship. Journal of Personality and Social Psychology, 96, 218-230.

Jones, C. J., \& Trickett, E. J. (2005). Immigrant adolescents behaving as culture brokers: A study of families from the Former Soviet Union. Journal of Social Psychology, 145, 405-427.

Jurkovic, G. J. (1997). Lost childhoods: The plight of the parentified child. New York, NY: Brunner Mazel.

Kahn, R. E., Holmes, C., Farley, J. P., \& Kim-Spoon, J. (2015). Delay discounting mediates parent-adolescent relationship quality and risky sexual behavior for low self-control adolescents. Journal of Youth and Adolescence, 44, 1674-1687.

Kearney, J., \& Bussey, K. (2014). The longitudinal influence of self-efficacy, communication, and parenting on spontaneous adolescent disclosure. Journal of Research on Adolescence, 25(3), 506-523.

Killoren, S. E., \& Deutsch, A. R. (2014). A longitudinal examination of parenting processes and Latino youth's risky sexual behaviors. Journal of Youth and Adolescence, 43(12), 1982-1993.

Knox, S., \& Burkard, A. W. (2009). Qualitative research interviews. Psychotherapy Research, 19(4-5), 566-575.

Kosner, A., Roer-Strier, D., \& Kurman, J. (2014). Changing familial roles for immigrant adolescents from the former Soviet Union to Israel. Journal of Adolescent Research, 29(3), 356-379.

Kudo, F. T., Longhofer, J. L., \& Floersch, J. E. (2012). On the origins of early leadership: The role of authoritative parenting practices and mastery orientation. Leadership, 8, 345-375.

Kvale, S. (1996). Interviews: An introduction to qualitative research interviewing. Thousand Oaks, CA: Sage.

Kwak, K. (2003). Adolescents and their parents: A review of intergenerational family relations for immigrant and non-immigrant families. Human Development, 46, 115-136.

Leipzig, C., (2006). When Russians come to therapy. The American Journal of Family Therapy, 34, 219-242. 
International Journal of Child, Youth and Family Studies (2016) 7(1): 1-26

Lerner, J., Rapoport, T., \& Lomsky-Feder, E. (2007). The ethnic script in action: The regrounding of Russian Jewish immigrants in Israel. Ethos, 35(2), 168-195.

Liew, J., Kwok, O., Chang, Y., Chang, B. W., \& Yeh, Y. (2014). Parental autonomy support predicts academic achievement through emotion-related self-regulation and adaptive skills in Chinese American adolescents. Asian American Journal of Psychology, 5(3), 214-222.

Lincoln, Y., \& Guba, E. (1985). Naturalistic Inquiry. Beverly Hills, CA: Sage.

Maccoby, E. E., \& Martin, J. A. (1983). Socialization in the context of the family: Parentchild interaction. In P. Mussen \& E. M. Hetherington (Eds.), Handbook of Child Psychology. Vol. 4: Socialization, personality, and social development (pp. 1-101). New York, NY: Wiley.

Mann, M. (2004). Immigrant parents and their emigrant adolescents: The tension of inner and outer worlds. The American Journal of Psychoanalysis, 64(2), 143-153.

Mirsky, J. (2012). Social deviance among immigrant adolescents from the former Soviet Union in Israel: Data and risk factors. Anales de Psicología, 28(3), 675-682.

Mirsky, J., \& Prawer, L. (2003). Immigrating as an adolescent. In T. Horowitz (Ed.), Children of Perestroika in Israel (pp. 72-118). Lanham, MD: University Press of America.

Moed, A., Gershoff, E. T., Eisenberg, N, Losoya, S. Spinrad, T. L., \& Liew, J. (2014). Parent-adolescent conflict as sequences of reciprocal negative emotion: Links with conflict resolution and adolescents' behavior problems. Journal of Youth and Adolescence, 44(8), 1607-1622. doi:10.1007/s10964-014-0209-5

Moustakas, C. (1994). Phenomenological research methods. Thousand Oaks, CA: Sage.

Nesteruk, O., \& Marks, L. (2009). Grandparents across the ocean: A qualitative study of Eastern European immigrants' struggle to maintain intergenerational relationships. Journal of Comparative Family Studies, 40(1), 77-95.

Nesteruk, O., \& Marks, L. D. (2011). Parenting in immigration: Experiences of mothers and fathers from Eastern Europe raising children in the United States. Journal of Comparative Family Studies, 42, 809-825.

Norrick, N. R., \& Spitz, A. (2010). The interplay of humor and conflict in conversation and scripted humorous performance. International Journal of Humor Research, 23(1), 83111.

Oznobishin, O., \& Kurman, J. (2009). Parent-child role reversal and psychological adjustment among immigrant youth in Israel. Journal of Family Psychology, 23, 405415. doi:10.1037/a0015811

Perälä-Littunen, S., \& Böök, M. L. (2012). The beginning and end of parental responsibility: Finnish parents’ view. Journal of Comparative Family Studies, 43, 925-941.

Ponizovsky, Y., Kurman, J., \& Roer-Strier, D. (2012). When role reversal and brokering meet: Filial responsibility among young immigrants to Israel from the former Soviet Union. Journal of Family Psychology, 26(6), 987-997. 
International Journal of Child, Youth and Family Studies (2016) 7(1): 1-26

Portes, A., Fernandez-Kelly, P., \& Haller, W. (2009). The adaptation of the immigrant second generation in America: A theoretical overview and recent evidence. Journal of Ethnic and Migration Studies, 35(7), 1077-1104.

Ravens-Sieberer, U., Erhart, M., Gosch, A., \& Wille, N. (2008). Mental health of children and adolescents in 12 European countries: Results from the European KIDSCREEN study. Clinical Psychology and Psychotherapy, 15(3), 154-163.

Rinaldi, C. M., \& Howe, N. (2012). Mothers' and fathers’ parenting styles and associations with toddlers' externalizing, internalizing, and adaptive behaviors. Early Childhood Research Quarterly, 27, 266-273.

Ritsner, M., Modai, I., \& Ponizovsky, A. (2000). The stress-support patterns and psychological distress of immigrants. Stress Medicine, 16, 139-147.

Roer-Strier, D., \& Kurman, J. (2009). Combining qualitative and quantitative methods to study perceptions of immigrant youth. Journal of Cross-Cultural Psychology, 40(6), 988-995.

Roer-Strier, D., \& Rosenthal, M. K. (2001). Socialization in changing cultural contexts: A search for images of the "adaptive adult”. Social Work, 46(3), 215-228.

Roeters, A., van der Lippe, T., \& Kluwer, E. S. (2010). Work characteristics and parent-child relationship quality: The mediating role of temporal involvement. Journal of Marriage and Family, 72, 1317-1328.

Sartaj, B., \& Aslam, N. (2010). Role of authoritative and authoritarian parenting in home, health and emotional adjustment. Journal of Behavioral Sciences, 20(1), 47-66.

Saxena, D., \& Sanders, G. F. (2009). Quality of grandparent-grandchild relationship in Asian-Indian immigrant families. The International Journal of Aging and Human Development, 68(4), 321-337.

Shkedi, A. (2003). Words of meaning: Qualitative research - theory and practice. Tel-Aviv, Israel: Ramot.

Shor, R. (1999). Inappropriate child rearing practices as perceived by Jewish immigrant parents from the former Soviet Union. Child Abuse and Neglect, 23(5), 487-499.

Shor, R. (2000). Jewish immigrant parents from the former Soviet Union: A method for studying their views of how to respond to children's misbehavior. Child Abuse and Neglect, 24(3), 353-362.

Slagt, M., Deković, M., De Haan, A. D., Van den Akker, A. L., \& Prinzie, P. (2012). Longitudinal associations between mothers' and fathers' sense of competence and children's externalizing problems: The mediating role of parenting. Developmental Psychology, 48(6), 1554-1562.

Slonim-Nevo, V., Sharaga, Y, \& Mirsky, J. (1999). A culturally sensitive approach to therapy with immigrant families: The case of Jewish emigrants from the former Soviet Union. Family Process, 38, 445-461.

Sowa, H., Crijnen, A. A. M., Bengi-Arslan, L., \& Verhulst, F. C. (2000). Factors associated with problem behaviors in Turkish immigrant children in the Netherlands. Social Psychiatry and Psychiatric Epidemiology, 35(4), 177-184. 
International Journal of Child, Youth and Family Studies (2016) 7(1): 1-26

Steinberg, L., Elmen, J. D., \& Mounts, N. S. (1989). Authoritative parenting, psychosocial maturity, and academic success among adolescents. Child Development, 60, 1424-1436.

Strier, R., \& Roer-Strier, D. (2005). Fatherhood and immigration: Perceptions of Israeli immigrant fathers from Ethiopia and the former Soviet Union. Families in Society, 86, 121-133.

Trickett, E. J., \& Jones, C. J. (2007). Adolescent culture brokering and family functioning: A study of families from Vietnam. Cultural Diversity and Ethnic Minority Psychology, 13(2), 143-150.

Turney, K., \& Kao. G. (2009). Barriers to school involvement: Are immigrant parents disadvantaged? The Journal of Educational Research, 102, 257-271.

Walsh, S., Shulman, S., Bar-On, Z., \& Tsur, A. (2006). The role of parentification and family climate in adaptation among immigrant adolescents in Israel. Journal of Research on Adolescence, 16, 321-350. doi:10.1111/j.1532-7795.2006.00134.x

Walsh, S. D., Djalovski A., Boniel-Nissim M., \& Harel-Fisch, Y. (2014). Parental, peer and school experiences as predictors of alcohol drinking among first and second generation immigrant adolescents in Israel. Drug and Alcohol Dependence, 138, 39-47.

Waylen, A., \& Stewart-Brown, S. (2010). Factors influencing parenting in early childhood: A prospective longitudinal study focusing on change. Child: Care, Health and Development, 36, 198-207.

Weisskirch, R. S., \& Alva, S. A. (2002). Language brokering and the acculturation of Latino children. Hispanic Journal of Behavioral Sciences, 24, 369-378.

Yakhnich, L. (2008). Immigration as a multiple-stressor situation: Stress and coping among immigrants from the former Soviet Union in Israel. International Journal of Stress Management, 15, 252-268.

Yakhnich, L. (2010). Immigrant adolescents from the Former Soviet Union in Israel - risk and adaptation. Hed HaUlpan HaHadash, 97, 64-70.

Yakhnich, L., \& Teichman, M. (2015). Immigrant family in distress: Assisting immigrant parents of juvenile delinquents. International Journal of Child, Youth and Family Studies, 6(1), 1-16.

Yau, J., \& Smetana, J. (2003). Adolescent-parent conflict in Hong Kong and Shenzhen: A comparison of youth in two cultural contexts. International Journal of Behavioral Development, 27(3), 201-211. 